Research, part of a Special Feature on Implementing Participatory Water Management: Recent Advances in Theory, Practice and Evaluation

\title{
An Empirical Analysis of Stakeholders' Influence on Policy Development: the Role of Uncertainty Handling
}

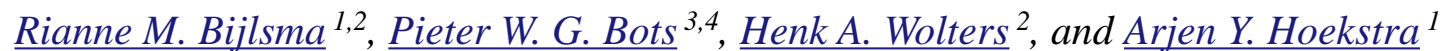

\begin{abstract}
Stakeholder participation is advocated widely, but there is little structured, empirical research into its influence on policy development. We aim to further the insight into the characteristics of participatory policy development by comparing it to expert-based policy development for the same case. We describe the process of problem framing and analysis, as well as the knowledge base used. We apply an uncertainty perspective to reveal differences between the approaches and speculate about possible explanations. We view policy development as a continuous handling of substantive uncertainty and process uncertainty, and investigate how the methods of handling uncertainty of actors influence the policy development. Our findings suggest that the wider frame that was adopted in the participatory approach was the result of a more active handling of process uncertainty. The stakeholders handled institutional uncertainty by broadening the problem frame, and they handled strategic uncertainty by negotiating commitment and by including all important stakeholder criteria in the frame. In the expert-based approach, we observed a more passive handling of uncertainty, apparently to avoid complexity. The experts handled institutional uncertainty by reducing the scope and by anticipating windows of opportunity in other policy arenas. Strategic uncertainty was handled by assuming stakeholders' acceptance of noncontroversial measures that balanced benefits and sacrifices. Three other observations are of interest to the scientific debate on participatory policy processes. Firstly, the participatory policy was less adaptive than the expert-based policy. The observed low tolerance for process uncertainty of participants made them opt for a rigorous "once and for all" settling of the conflict. Secondly, in the participatory approach, actors preferred procedures of traceable knowledge acquisition over controversial topics to handle substantive uncertainty. This excluded the use of expert judgment only, whereas the experts relied on their judgment in the absence of a satisfactory model. Thirdly, our study provides empirical evidence for the frequent claim that stakeholder involvement increases the quality of the knowledge base for a policy development process. Because these findings were obtained in a case that featured good process management and a guiding general policy framework from higher authorities, they may not generalize beyond such conditions.
\end{abstract}

Key Words: environmental policy; framing; participation; policy development; policy process; stakeholder involvement; uncertainty

\section{INTRODUCTION}

European legislation such as the Water Framework Directive (EU 2000, Article 14) encourages the involvement of affected parties in the management of natural resources. This can be seen as a break with the approach in which stakeholder needs are taken care of by public agencies and experts (De Marchi 2003). In the latter "expert-based approach", the competent authority frames the problem, performs the policy analysis (or outsources it to experts), and balances the stakes. An expert-based approach may include some interaction with stakeholders, but not to the extent that characterizes a "participatory approach". In a participatory approach, stakeholders are at least consulted in a structured way so that they can influence problem framing, policy analysis, and/or decision-making (Arnstein 1969, Biggs 1989).

Stakeholder participation in environmental policy development is associated with benefits for the 
substantive quality of policy and its legitimacy and implementation, and for the development of social capital for involved parties (Fiorino 1990, Laird 1993, Smith Korfmacher 2001, Beierle and Cayford 2002). In this article, we focus mainly on the influence of stakeholder involvement on the development of substance in policy development, notably the framing of the policy problem, the policy analysis and design, and the creation and use of knowledge.

We view participatory policy development as a complex, path-dependent process in which actors, not knowing exactly how their interests will be affected by future developments, seek to reach an understanding about the policy situation and the possible options and their consequences, in order to coordinate their actions through agreement. When actors have potentially conflicting interests and asymmetric access to resources, this process will comprise communicative action based on reason and argument, as well as self-centered action based on strategic calculation. Baccaro (2006) convincingly argues that what happens in a successful participatory process is probably some form of "mixed-motive" bargaining (Walton and McKersie 1965, Elster 1989, Scharpf 1997) in which actors try to increase the total benefit by creatively combining issues and options (integrative bargaining to "enlarge the pie"), but also try to frame the situation in a way that will maximize their own advantage when it comes to bargaining about the final policy decision (distributive bargaining to "make sure we get a big piece"). The integrative mode involves open and truthful communication, whereas the distributive mode entails intentional misinformation.

Following this line of thought, we conceptualize participatory policy development as an ongoing multi-actor search for a frame that gives all actors sufficient certainty that within this frame they will be able to promote, or at least protect, their own interests. The term "frame" here denotes an "interactional co-construction" (Dewulf et al. 2009) that gives meaning to a situation. A joint frame is constructed from the individual frames of actors, which reflect their ideas about facts, interests, norms, values, rules, and responsibilities, and their own position within it (Schön and Rein 1994). This joint frame constructing occurs in a process of social interaction that Putnam and Holmer (1992) refer to as "issue development". It entails agenda setting because the frame highlights some problems while obscuring others (Entman 1993, Fischer 2003). Actors who feel comfortable with the frame (e.g., because it reflects their interests and offers good bargaining prospects) will push towards closure, whereas actors who feel unsure (e.g., because consequences of options are uncertain or procedures are ambiguous) will endeavor to defer closure in the hope of change towards a more favorable frame. Frame development thus is a dynamic process: as the frame establishes pertinent aspects (causes, options, effects, constraints-social, technical, financial, ...), it drives the collection of new knowledge. This may raise new issues that prompt frame changes; actors who become doubtful about whether the frame is still advantageous for them will try to redress this, and so on.

Based on these assumptions, we describe and analyze the development of the frame in two policy development processes - a participatory approach and an expert-based approach-for the same case: the development of a local water management plan. Since the perception and resolution of uncertainties is an important dynamic driving the process (Koppenjan and Klijn 2004, Abbott 2005), we try to identify and characterize the uncertainties that were the cause of reframing and the methods that actors used to handle these uncertainties. We expect that comparing the participatory process to the process without direct stakeholder involvement will help us understand the process of framing and analysis. The "one case, two processes" comparison also allows us to look in more detail at the substantive knowledge that stakeholders contributed to the policy development process and to elaborate on the claim that stakeholders' participation may improve the knowledge base (Beierle and Konisky 2001).

In the Methods section, we first present the conceptual framework that we used in our analysis and the comparison of the two policy development processes and then outline the setup of our study. In the Results section, we describe the essential events for both processes, identify and categorize the uncertainties that played a role, and describe the uncertainty handling methods that were used to resolve them. In the Discussion section, we compare our results to those reported in other empirical case studies that address the influence of stakeholder involvement (Stern and Fineberg 1996, Wynne 1996, Clark and Murdoch 1997, Beierle and Konisky 2001, Maxim and Van der Sluijs 2007). Although our study is mainly descriptive, we offer 
some tentative explanations for the observed behaviors and outcomes. We also reflect on the advantages and limitations of our analysis, notably our focus on uncertainty and uncertainty handling methods.

\section{METHODS}

\section{Analytic framework}

We assume that joint frame construction occurs in a continuous process of scoping and sense-making, in which actors seek to incorporate relevant parts of their individual frame into the joint frame to create opportunities for themselves and/or others. In this process, establishing the nature, scope, and relevant aspects of the problem, and collecting, analyzing, and synthesizing knowledge about these aspects (ranging from physical processes to actor preferences to socio-political institutions) are so tightly connected that we do not distinguish between framing activities or policy analysis and design activities. We do make a conceptual distinction between the process and the knowledge that is used and produced in the process. From now on, we will refer to the former as "framing and analysis" and to the latter as "the knowledge base". There is a constant interaction between the two because the framing and analysis determine the relevant knowledge, while the availability of knowledge influences the actors' strategies in framing and analysis. We assume that actors will especially attempt reframing when they believe that the present frame contains uncertainties that pose the risk of a loss (Kahneman and Tversky 2000). This leads us to focus on the perception and resolution of uncertainties during framing and analysis.

\section{Types of uncertainty}

Following Koppenjan and Klijn (2004), we distinguish between substantive, strategic, and institutional uncertainty:

Substantive uncertainty refers to a lack of knowledge about the substance (content, subject matter) of the policy problem, e.g., the relation between soil properties and vegetation, the volatility of market prices, or the effect of land use on groundwater. This lack may be experienced because there is no information on the subject, but also because the available information is too abundant or is ambiguous or conflicting.

Strategic uncertainty refers to a lack of knowledge about how actors will anticipate and respond to each other's actions. This is inevitable because actors, due to their own frames, will perceive the risks and opportunities (their own and those of other actors) in a given situation differently and will develop different strategies while second-guessing those of other actors. The outcomes of these strategies are highly unpredictable.

Institutional uncertainty refers to a lack of knowledge about formal competences, procedures, and conventions. It is the result of actors belonging to different organizations, administrative levels, and networks, and hence being guided by different concepts, tasks, and opinions, and respecting different rules. This makes the organization of the policy development process very unpredictable, even more so when actors are involved in multiple policy arenas.

When analyzing a policy development process, we infer the occurrence of uncertainty from the actors' behavior. Direct indications are the explicit mentioning of uncertainty and the performance of an uncertainty analysis. Indirect indicators are disagreement, an attitude of sit and wait for the other actors to move first (paralysis in the process), the exploration of alternative modes of action, or a search for information.

\section{Uncertainty handling methods}

To handle the uncertainties, actors may opt for several methods. The overview in Table 1 is inspired by Termeer and Koppenjan (1997), Walker and Marchau (2003), and Van Asselt (2005). Because the handling methods for strategic uncertainty and institutional uncertainty are quite similar (they deal with unpredictable actor behavior), we have grouped them under the term "process uncertainty". Abbott (2005) uses this term when making a similar distinction. Substantive uncertainty handling methods focus on the cognitive dimension, while process uncertainty handling methods focus on the social dimension. We further distinguish between passive and active methods. Passive methods preclude the need for more active handling of uncertainty. Each method is identified with a 
mnemonic, which we use to code our observations in the Results section.

Note that we can observe passive strategy ignorance (p-I) only through comparison of the participatory and the expert-based process. When an uncertainty is observed in one approach but not in the other, we identify this as ignorance on the part of the actors in the latter approach.

\section{The knowledge base}

Stakeholders often contribute detailed knowledge about specific aspects to the knowledge base, indicate omissions and flaws, and criticize analysis methods and model predictions of the effects of policies (Stern and Fineberg 1996, Wynne 1996, Clark and Murdoch 1997, Beierle and Konisky 2001). To assess whether this also occurred in our case study, we compared the knowledge base jointly developed by experts and stakeholders with the knowledge applied by the experts only. We looked for substantive (e.g., relevant hydrological models, ecological expertise, local system knowledge) as well as process content (e.g., knowledge about actor preferences, formal competences, pertinent rules and regulations). We used the expert knowledge base as the point of reference and then looked for additions and corrections to and omissions from this knowledge in the participatory approach. An addition is defined as supplementary knowledge accepted by all actors, a correction as the replacement or deliberate rejection of knowledge with the support of all actors, and an omission as relevant knowledge overlooked due to process dynamics. Knowledge that is applied but is unacceptable to one or more actors was labeled as nonvalidated knowledge. We did not consider superfluous knowledge (Van de Riet 2003), i.e., knowledge brought in that was not relevant to policy development.

\section{Case study}

In 2005, the Dutch national government required the formulation of local water management plans (Gewenst Grond-en Oppervlaktewater Regime [GGOR]) for all Natura 2000 areas by the end of 2007. Our case study concerns the Natura 2000 area Bargerveen and its surrounding agricultural land, situated in the province of Drenthe in the northeast of the Netherlands. The most important objective set for this area by the Dutch Ministry of
Agriculture, Nature and Food is the development of high peat. High peat growth requires a rise in the water table, whereas the agriculture on the adjoining land requires lower water levels. This divergence between stakes constituted the core of a long, drawnout local water management conflict. An earlier negotiation process in 2001 had ended without result, and the Natura 2000 objectives only reinforced the clash of interests. The water board initiated a participatory process to develop the GGOR. We outline the setup of this process and then describe why and how we conducted a second process, this time applying an expert-based approach to the same case.

\section{The participatory approach}

This approach involved a "sounding board group" whose members were selected in such a way that all stakes were represented. The level of control for this group can be characterized as consultation with some collaborative elements (Biggs 1989, Barreteau et al. 2010), or as placation on Arnstein's (1969) ladder of participation. The actors collaborated closely through an exchange of knowledge and advice on decisions, but the key decisions remained with the water board. The water board devolved the policy development process to a project team consisting of an external process manager, several water board employees, and an external consultant for hydrological modeling. Throughout the entire process, the first three authors of this article were involved as co-designers, facilitators, and evaluators.

The most important stakeholders were the nature conservationists and the farmers. Others were the residents of surrounding villages and a few entrepreneurs. The GGOR plan had to be formally approved, first by the board of directors of the water board, then by the province of Drenthe, and ultimately by the Ministry. The sounding board group consisted in total of 30 delegates. The group first convened in October 2006 and agreed on the objective of determining a GGOR for Bargerveen and the surrounding area. The group met twice a year in its complete configuration (four meetings in total). Between meetings the project team bilaterally interacted up to three times with both the farmers and the nature conservationists (sometimes in combination with the Province). The GGOR was established in April 2008. We refer to Bots et al. (2011) for more details. 
Table 1. Methods for handling uncertainty.

Passive methods

\section{Active methods}

\section{Increase uncertainty tolerance}

Substantive uncertainty

Process uncertainty

(tp-TB)

\section{Reduce uncertainty}

Substantive uncertainty

(rs-KA)

(rs-EBAK)

Process uncertainty

$$
\text { rp-P }
$$

rp-C
Ignorance: the policy development process proceeds without an observable choice regarding the handling of an uncertain aspect

Recognized Ignorance: the uncertain aspect is identified and expressed, but a decision is taken without considering other options

Avoidance: uncertainty is avoided by restricting the scope of the joint frame, e.g., by leaving out or deferring measures of which the effectiveness and/or feasibility (technical and/or political) are uncertain
Transparency: share information about the origin and quality of available knowledge and make the acquisition of new knowledge traceable, e.g., by involving actors in modeling and data collection activities

$$
\text { Safeguards: work with bandwidths in calculations and communicate results using orders of }
$$
magnitude rather than precise figures

Trust Building: increase trust among actors by furthering social interaction, encouraging information sharing, and emphasizing interdependencies

Knowledge Acquisition: consult experts, study scientific literature, collect empirical data, perform model-based simulations, analyze and interpret findings, etc.

Establishing Best Available Knowledge: discuss rivaling knowledge and knowledge limitations (qualitative), analyze uncertainty (quantitative), and make assumptions

Procedures: develop formal rules and procedures that reduce the actors' room for unexpected strategic behavior

Commitment: involve influential actors who can assume decision-making authority and emphasize the benefits of reaching an agreement

\section{The expert-based approach}

We were curious to know how framing and analysis might have taken place if no stakeholders had been involved. We presumed that even a simulated expert-based approach to the Bargerveen case could provide us with data on frames, uncertainties, and uncertainty handling methods that, when compared to those observed in the participatory process, would improve our understanding of this process.
The design of a realistic expert-based process needed some consideration. The involvement of the experts from the participatory approach would be problematic. Involving these same experts before or parallel to the participatory process might give stakeholders the impression that the competent authority had already determined the policy to be implemented, irrespective of the outcome of their participation. This impression definitely needed to be avoided because it would deter stakeholders from 
taking an active part in the process. Conversely, an ex-post development would suffer from expert "contamination" because of the joint frame developed in the participatory process.

These considerations led us to invite a team of three professionals from a neighboring water board. They were recognized experts in the area of hydrology and spatial planning, and were familiar with the overall process of defining a GGOR but were not familiar with Bargerveen, although they were knowledgeable about similar areas. We did not have the resources to allow this second team to perform a full-scale policy development with its own data collection and modeling activities. During the simulation, we therefore let them use the knowledge developed during the participatory process, but only upon request: the experts had to precisely formulate their specific knowledge need and were given only what they asked for (insofar as it was available). In this way, we not only traced the use of knowledge but also avoided contaminating the experts with a problem frame from the participatory process. We observed stakeholders' additions to and correction of the knowledge base directly in the participatory process, and analyzed the stakeholders' proposed changes to knowledge brought in by the project team in this approach. We observed omissions of knowledge in the participatory approach by comparing knowledge use in both approaches.

The simulation was organized shortly before the stakeholder participation process came to a decision, and was led by the first two authors and the process manager of the stakeholder process. The expert team received a very brief introduction to the problem. We took special care not to give more information than had been available at the start of the stakeholder process.

\section{Data collection}

We analyzed the participatory approach by using minutes of the meetings and records of project team discussions that were aimed at interpreting the process dynamics. The first author performed the analysis, and the second author and the process manager verified the findings. Additional insight was obtained through direct observation of all meetings and through questionnaires and interviews that the first author conducted after both the first and third sounding board group meeting. The questionnaires asked for the participants' view on the context in which the process started and on the process management (Appendix 1). The semistructured interviews were based on the questions in the questionnaires and served to deepen the insight. We selected four members of the sounding board group for both interview rounds, each round inviting a different delegate from both the nature conservationist and the farmer group. The other interviews explored the views of stakeholders that attracted attention during the relevant meeting.

We analyzed the expert-based approach by using a transcript of the workshop. We urged the experts to think out loud, which enabled us to follow their arguments during policy development. In the debriefing afterwards, we asked them to elaborate further on the assessment criteria they applied, the assumptions they made regarding funding, what further steps they saw as being required, and the future they foresaw for the area. Finally, we asked for their reaction on the GGOR that had been developed in the participatory approach.

\section{RESULTS}

\section{Framing and analysis}

The activities are discussed first for the participatory approach then for the expert-based approach. For each approach, we first outline the process and the resulting preferred policy and then discuss the identified institutional, strategic, and substantive uncertainties; when they occurred in the process; how this affected framing; and how they were handled.

\section{Participatory policy development}

From the first meeting onwards, the participants were deeply aware of the conflicting stakes of farming and nature conservation. The existing water regime was advantageous for neither stake: it threatened the high peat and was suboptimal for agricultural production. The nature conservationists, strengthened by the Natura 2000 legislation, aimed for preservation of the peat vegetation and, where possible, for further growth. The farmers aimed for good economic conditions for farming. In particular, this meant clarity concerning the longterm prospects for agriculture in the area since the ongoing conflict kept them from investing in their farms. 
The sounding board group considered technical and spatial planning measures to improve the water levels for both parties. The technical measures were found to contribute only little to peat development, or their effects were uncertain. Therefore, these measures were unfavorable not only to the nature conservationists but also to the farmers, who feared that the conservationists would continue calling for additional measures, which would ensure the prospects for agriculture in the area remained uncertain. An option that emerged later in the process was the creation of a large hydrological buffer zone. This spatial planning measure would require the full cooperation of the Province and the Ministry, both in endorsement and in co-funding. No less important, it would also require cooperation of the farmers because they would have to sell some of their land.

The actors finally agreed on a GGOR that comprised a large buffer zone south of Bargerveen, plus the filling in of a few ditches within the area. The farmers would be financially compensated for the land and the relocation of several farms, while the drainage system of the remaining agricultural area would be optimized for farming.

\section{Uncertainties in the participatory policy development}

Several uncertainties played a role in the participatory process. Some were handled causally, while others became very important and were handled at crucial decision points. The actors showed institutional uncertainty about the roles and responsibilities of actors, about a threat to the longterm prospect of agriculture by the development of another nature area nearby in the policy arena, and about the exact nature objectives to be established by the Ministry. The interaction between actors caused strategic uncertainty. Throughout the process, substantive uncertainty about the most suitable locations for peat development, the required hydrological conditions, and the effects and costs of measures was handled actively. We discuss the uncertainties approximately in their sequence of appearance in the process, together with their handling.

At the start of the process, the influence of developments in another policy arena on the agricultural outlook was recognized. Although the farmers demanded clarity regarding their future prospects, they urged that these developments be ignored. The other actors acquiesced (p-RI).
Early in the process, the process manager asked the farmers and nature conservationists to specify what regime would be optimal from their perspective. This caused strategic uncertainty because the actors might demand higher groundwater levels (nature conservationists) or lower levels (farmers) than they actually wanted, anticipating a process of bargaining towards a compromise. This uncertainty was recognized but ignored ( $p-R I)$.

Establishing the optimal groundwater regime also required specification of the preferred locations for peat development. The nature conservationists and project team jointly (ts-T) handled the uncertainty related to this exercise. They collected information on area characteristics (rs-KA) by consulting both experts and an earlier area plan, and developed a map of ecological targets per location. Data discrepancies were discussed and could be resolved by establishing single best estimates (rs-EBAK). The process manager handled the uncertainty over the required hydrological conditions for peat by consulting a group of external peat experts (rs-KA), who provided expert judgment based on available scientific literature.

The optimal regimes, presented during the second sounding board meeting, were such that the water board concluded that the differences could not be reconciled in a feasible water management plan. The water board then framed the problem as a political choice between nature and agriculture that was beyond their jurisdiction and should be made by the Province. The board suggested that, pending this decision, they would declare the existing regime (possibly with minor changes) to be the GGOR Wishing to avoid (p-A) the strategic uncertainty of deferral, both farmers and nature conservationists strongly opposed this frame, arguing that the option of a hydrological buffer zone had not been investigated in sufficient depth to warrant such a move. The other sounding board group members concurred ( $\mathrm{p}-\mathrm{A})$, and the water board was asked to commission a model study to establish the effectiveness of this option. Lacking a good hydrological model, the water board was reluctant to commit to such a (costly) modeling study.

To implement a buffer zone, the water board needed the commitment of and funding by two other government bodies. The participants indicated there was ambiguity over roles and responsibilities of the different governmental bodies. The relatively new GGOR legislative framework was equivocal, and 
the procedure it outlined cut through the established consultative structures. During the first two sounding board group meetings, with their primary focus on open exchange of information (p-TB), this institutional uncertainty was acceptable to the participants. However, it stalled the process after the second sounding board group meeting, when the buffer zone option appeared.

There was uncertainty over whether the Province and the Ministry would both commit to the GGOR process, but without their funds the buffer zone option would not be feasible. The Province had the authority to change the spatial plan for the area and controlled certain funds that were earmarked for agricultural reform and nature development. The Ministry could still decide on the precise nature objectives for the area and also controlled some earmarked funds. The farmers insisted on clarity, arguing that further discussion about a buffer zone was meaningless without commitment to funding. They emphasized that a lack of financial support from the governmental authorities demonstrated that the objectives were overly ambitious, and they argued that the Ministry should use its authority to moderate the nature objectives for the area. The nature conservationists refused to agree to this frame, arguing that it was pointless to press for a decision in the absence of knowledge about the effectiveness of a buffer zone.

The substantive uncertainty about the effectiveness of a buffer zone combined with the institutional uncertainty over the commitment of the Province and Ministry to the GGOR process resulted in a complex strategic game. If the model study showed a buffer zone would be ineffective, the nature conservationists could still block the process by contesting the model. If a buffer zone were shown to be effective, its implementation would succeed only with the support of the Ministry and the Province. These actors could either commit to the process or not. For them, the risk of commitment was getting trapped into making a large financial contribution, but an inconclusive GGOR process would require them to make a precarious political choice between forfeiting agriculture in the area or moderating the nature objectives, with the risk of losing face at the European Union level.

The impasse was resolved in a face-to-face meeting between principals of the water board and the Province before the third sounding board meeting, in which the Province agreed to finance a buffer zone if it was shown to be effective (rp-C). Given this opening, the farmers consented to sell land, provided they were sufficiently compensated (rpC). These conditional commitments sufficed for the water board principal, who then approved a modest modeling study to provide rough estimates of the buffer zone's effectiveness. The idea of a quick modeling study to elicit the best available knowledge (rs-EBAK) was discussed in the sounding board group. The nature conservationists were reluctant but provisionally accepted the procedure (rp-P). The project team involved the nature conservationists and the Province in the modeling activity to stimulate acceptance (ts-T), and invited them to reflect on data, methods, intermediate results, and model limitations.

The stakeholders assessed the effects and societal impact of the measures in the bilateral meetings before and during the fourth sounding board group meeting (rs-KA). In the communication to the Province and the Ministry, the results were presented as orders of magnitude, indicating their uncertain nature (ts-S). Once the feasibility of the plan became more apparent, the Ministry was taken onboard by pointing at the unique window of opportunity (rp-C). In the fourth meeting, the group agreed on monitoring (rs-KA) of groundwater levels after implementation of the buffer zone. Uncertainty over the costs of the measures was explicitly mentioned and was handled by using a bandwidth (ts-S). During this fourth sounding board group meeting, the actors tentatively agreed on the policy.

During the framing and analysis, we observed several games that caused strategic uncertainty. A permanent concern was that all actors had the option of participating actively in the sounding board group, or staying away, or not speaking their minds. Active participation would allow them to bring in and defend their interests. On the other hand, raising a new issue near the closure of the process (end-ofgame behavior) might give them an advantage in the negotiations. To reduce strategic uncertainty for the participants, the process manager acted as mediator. She arranged face-to-face encounters for participants to meet and exchange considerations (tp-TB), stimulated agreement on procedures (rp-P, see Bots et al. [2011] for details), and time and again emphasized the actors' stakes in participating (rpC). The uncertainty regarding opportunistic end-ofgame behavior was handled by two procedural agreements (rp-P): firstly, the group would be entitled to ignore strategically withheld information, 
and secondly, if the scope of measures was to widen and affect additional stakeholders, these would be invited to join the sounding board group.

\section{The expert-based approach}

The expert team focused on satisfying the Natura 2000 objectives with the least sacrifices. Their objective was to keep the solution affordable for the water board and to avoid resistance by stakeholders in its implementation. The team interpreted the ambition of the nature objectives flexibly and searched for locations in the Bargerveen area for which the hydrological situation could be improved easily. The solutions considered were essentially the same as those in the participatory approach. The team first considered technical measures and then opted for a buffer zone. They indicated the need to contact the Province for authorization and funding of this zone. The team asked for the farmers' preferences and discovered their reluctance to give up activities. This was taken as a boundary condition for the further process. The experts built their plan on the premise that all parties would accept making small sacrifices.

In addition to filling in a few ditches inside Bargerveen, the resulting GGOR featured a small buffer zone southeast of it. The land for the buffer zone would be acquired via land consolidation based on attrition of the farming population. The farmers would be compensated through an improvement in the water regime for the agricultural land. The process manager of the participatory approach judged that this policy could have been acceptable to all stakeholders, and if not, that it would probably have been upheld in court because it met the procedural and substantive criteria for this kind of planning.

\section{Uncertainties in the expert-based policy development}

The experts barely discussed institutional uncertainty. Being aware of policy developments in other arenas, the team had doubts about the longterm prospects for agriculture in the Bargerveen area, and they did not rule out the fact that their formulated policy might be modified in future policy rounds. Furthermore, they expressed strategic uncertainty about the behavior of stakeholders in ex-post acceptance (or nonacceptance) of the policy. The experts voiced substantive uncertainty over good locations for peat development, the effect of measures on the hydrological conditions, and the societal impact of measures.

As a first step in the workshop, the experts requested (and received) information on required hydrological conditions for peat development (rs-KA). They appeared to interpret these conditions more loosely than was done in the participatory process. When looking for locations with peat growth potential, the team relied on their expert judgment to interpret the various ecological, geological, and hydrological maps (rs-KA). To handle strategic uncertainty, the team requested (and received) the preferences of the farmers (rs-KA). They made assumptions about the preferences and behavior of the other actors (rsEBAK). They searched for noncontroversial measures that could be implemented by the water board (p-A), and extended the implementation of measures over a long time frame so as to benefit from windows of opportunity, such as the retirement of farmers ( $\mathrm{p}-\mathrm{A})$. The team made assumptions about the societal impacts (rs-EBAK).

The experts stated the need to communicate to the Province the uncertainty over the long-term prospects for agriculture (ts-S). The uncertainty of whether their plan would endure was discussed but was not handled, and the policy time frame was left implicit (p-RI). The experts overlooked the interest of the farmers in obtaining clarity on this point $(\mathrm{p}-$ I). To handle uncertainty about the effect of measures, the team would have preferred model calculations, but lacking a detailed model, they relied on expert knowledge (rs-KA). Uncertainty was communicated less explicitly than in the participatory process ( $\mathrm{p}-\mathrm{RI})$.

\section{The knowledge base}

In the participatory approach, the stakeholders added to and corrected the knowledge of the project team. We did not observe discarding or ignorance of knowledge that was considered relevant in the expert-based approach, nor inclusion of nonvalidated knowledge. We discerned several categories of stakeholders' contributions and corrections:

Background information: The farmers contributed knowledge about earlier research into drainage possibilities and bottlenecks for agriculture, while the conservationist added knowledge about a 
historical hydrological study. Additionally, the participants shared the ins and outs of sensitivities of the conflict, such as the distrust between farmers and conservationists.

Area characteristics: The nature conservationists contributed information about favorable locations for peat development and necessary hydrological conditions. The farmers gave information about wet spots of land and their management practices, such as their crop rotation system, as a basis for determining the optimal groundwater regime. The conservationists corrected the model calculations by pointing out that a ditch in the model had actually been filled in.

Model application and interpretation: The stakeholders contributed to the interpretation of peculiar model outcomes, such as excessive seepage, by sharing their knowledge about area characteristics. The conservationists corrected the application of model extrapolation, pointing out the many uncertainties involved.

Stakeholder preferences: The farmers and conservationists amended the knowledge about their main concerns. The conservationists valued the health of the overall ecosystem over peat development at specific locations. The farmers clarified the long-term prospects for agriculture in the area rather than preserving as many farms as possible. The farmers also indicated a preference for local drainage control.

Local developments: A few farmers shared, off the record, the fact that they would be willing to sell their property. A resident knew that a road that would need to be elevated in the GGOR plan was already due for reconstruction.

Creative policy design: The farmers contributed the idea of raising farms on artificial mounds in the buffer zone to limit the number of farmers having to leave the area.

Competences and procedures: The Province and Ministry shared their interpretation of procedures. For example, the Ministry representative stated the intention to leave the tentative nature objectives unchanged. The principals of these organizations also exchanged ideas about their roles.

\section{DISCUSSION}

\section{The influence of uncertainty handling on framing and analysis}

Compared to the policy developed by experts, the policy developed with stakeholder participation involved more resources, had a larger scope, and required the cooperation of more stakeholders. We discuss the differences in the two policy development processes, consider mechanisms that might explain our observations, and compare the findings to our reference case studies, by which we mean other empirical case studies that address the influence of stakeholder involvement (Stern and Fineberg 1996, Wynne 1996, Clark and Murdoch 1997, Beierle and Konisky 2001, Maxim and Van der Sluijs 2007).

The dominant institutional uncertainty identified in the participatory process was uncertainty about actors' roles, which the group handled by arranging active commitment. Strategic uncertainty was handled through trust-building, commitment, and procedures. The participants used what power they had to try to influence the frame to their advantage, mostly widening it. Since the participants did not want the decision to be moved beyond their influence, a logical reaction to this process uncertainty was to enlarge the frame so as to internalize it. We suggest that the low tolerance of process uncertainty was driven by the stakeholders: the farmers needed a firm, long-term agreement that would warrant new investments in their farms, and the nature conservationists wanted to maximally exploit the window of opportunity opened by the acquired Natura 2000 status. Interestingly, we see two proposals to narrow the frame, which may also be explained by intolerance of process uncertainty. The farmers' (successful) urging to exclude developments in surrounding nature areas reduced the risk of actors emphasizing the precarious position of agriculture in the region. We suggest that the (unsuccessful) proposal of the water board to narrow the frame and defer the actual choice to higher authorities was rejected because it would increase, rather than decrease, process uncertainty for most stakeholders.

The dominant institutional uncertainty identified in the expert-based approach was uncertainty about developments in other arenas, which the experts avoided by anticipating future windows of 
opportunity. By aiming for measures within the reach of the water board, they avoided uncertainty about roles and responsibilities. The experts reduced strategic and substantive uncertainties by making assumptions, collecting knowledge on preferences and measure feasibility, while balancing benefits and sacrifices for stakeholders. In this process, they ignored some assessment criteria that were important to the stakeholders in the participatory process.

Looking at our reference case studies, we equally see a broader frame in participatory policy development (Stern and Fineberg 1996, Beierle and Konisky 2001), and a tendency to reduce the frame in an expert-based approach (Wynne 1992a), a phenomenon also discerned by Kickert et al. (1997). Fritsch and Newig (2006) address frame reduction in participatory policy development, and offer as explanation that the interest of local actors tends to focus on time horizons that are not large enough to internalize the negative externalities. Such temporal myopia seemed to play no role in our case.

An interesting observation is that the expert-based policy is more adaptive, whereas the participatory approach fixed the policy for the next 25 years. This is at odds with the expected urge of stakeholders to reach agreement despite uncertain information by making adaptation part of the preferred policy (Ehrmann and Stinson 1999). We again find the low tolerance of (future) process uncertainty at the base of this difference; adaptive management sustains process uncertainty. The context of the case, a persisting conflict, decreased the tolerance of process uncertainty even further, since farmers had experienced the disadvantage of process uncertainty over a long time.

The two approaches identified similar substantive uncertainties and applied similar handling methods, except for the measure effect uncertainty. The experts relied on their judgment in the absence of a detailed model, whereas in the participatory approach this method was rejected in favor of model calculations. The model became a decisive factor in determining the width of the buffer zone. The calculations were favored because they would make information collection traceable and formal, thus developing trust. This finding supports the proposition by Kickert et al. (1997) that formalizing procedures in complex processes overcomes process uncertainty. Our reference case studies do not show this in action.
Finally, we noticed that the participatory approach paid explicit attention to communicating uncertainty in analysis results, while the expert-based approach did this less. Case studies by Wynne (1992b) and Stern and Fineberg (1996) show similar observations. We tentatively offer two explanations: (1) the experts felt less need to communicate uncertainty because the impact of the measures they proposed was smaller and the effects were presented qualitatively, and/or (2) the experts felt more confident because of their prior experience with the measures and the absence of stakeholders' critique and insistence on transparency.

\section{The knowledge base}

Like all of our reference case studies, we found that the stakeholders contributed to the knowledge base. Being more detailed, our analysis enables us to distinguish categories for stakeholders' contributions: background information, area characteristics, model application and interpretation, stakeholder preferences, knowledge of local developments, creative policy design, and competences and procedures. The knowledge had a substantial influence on the policy development.

The background information and knowledge of local developments saved on costs of both the analysis and the measures. The knowledge of area characteristics made the analysis more accurate and better tailored to the local situation. The stakeholder preferences diverged considerably from those initially assumed by the project team, and this changed the policy assessment criteria. The discussion of competences and procedures and the information that some farmers would be willing to sell their property provided a crucial opening for the process.

Because no knowledge was discarded, our study provides additional empirical evidence to support the frequent claim that stakeholder involvement increases the quality of the knowledge base for a policy development process. Viewing the process as one of mixed motive bargaining, we find it difficult to differentiate between the motives of stakeholders to share specific knowledge. We see more strategic contributions to the optimal groundwater regime, stakeholder preferences, and correction of model extrapolation. We also find more neutral contributions in the interpretation of model outcomes and the mentioning of the plan for 
road elevation. None of the actors contributed information that directly harmed their stake.

\section{Focus on uncertainty handling}

The focus on uncertainty necessarily highlights decision points in the process and helps clarify and characterize the actions that further the process. This aided our comparison of the two processes. Differentiating between types of uncertainty makes the interaction between substance and process more apparent: in the participatory process, we could see how establishing the optimal groundwater regime for peat development and for agriculture led to a strategic move by the water board, and we elucidated the complex negotiation process that preceded the decision to perform model calculations. We could also see interaction between methods to handle process and substantive uncertainty, for example, combining the search for best available knowledge with seeking commitment to accept the results. Reviewing the literature, however, we found that substantive uncertainty has been a topic mainly in policy analysis and operational research (Morgan and Henrion 1990, Walker et al. 2003), while process uncertainty is discussed mainly in the field of policy networks and process management (Kickert et al. 1997, Rhodes 1997). Studies that explicitly address both process and substantive uncertainty (Wynne 1992a, Koppenjan and Klijn 2004, Brugnach et al. 2008) are rare. We suggest that more research into the interaction between the handling of different types of uncertainty is warranted.

In some policy science literature that discusses decision-making under uncertainty (Scharpf 1997, Walker et al.2003), uncertainty is a given, stemming from the policy context. In our perspective, uncertainty is a dynamic variable, dependent on perception and influenced by framing, analysis, and the interaction of actors in the process. Uncertainty provides a motive for reframing until all actors feel sufficiently comfortable with the frame. We further elaborated this view of uncertainty as an important dynamic driving the process, driven by the work of Koppenjan and Klijn (2004) and Abbott (2005). The uncertainty perspective, we speculate, may provide valuable insight when considering alternative process management interventions in a participatory approach. In our case, the process manager stimulated firm commitment to handle process uncertainty. An alternative method (see Table 1) would have been to put increased emphasis on trust building. This in turn could have enabled a more adaptive policy. To give another example, the team of experts avoided institutional uncertainty about roles and responsibilities by frame reduction. They might also have opted for handling it actively, for example, by involving the Province and the Ministry in policy design to seek their commitment. This could have made the resulting policy more robust in case of change in future policy rounds but would also have involved complexity due to strategic behavior of these actors. Focusing on decision points and uncertainties and comparing the potential of methods in Table 1 will enhance reflection on alternative methods to advance the policy development process. We would therefore posit the perception of uncertainty as a variable that should be studied in its own right, seeing uncertainty tolerance and uncertainty reduction as steering variables and uncertainty handling methods as a mechanism for intervention.

Identifying uncertainties and handling methods facilitated our comparison of the participatory and the expert-based processes. We believe that it would equally facilitate the comparison of different participatory processes and support process evaluation by providing additional information on evaluation criteria such as the influence of stakeholders and the transparency of decisions (see Rowe and Frewer 2004). This information complements traditional data collection on individual actor experiences and motivations through questionnaires and mapping of actor frames.

\section{Limitations of the study}

Given the available resources, the level of detail of the expert-based approach was limited. It was a simulation in which the experts had restricted time, tapped from the knowledge base of the participatory approach, and eventually outlined preferred measures and subsequent steps. Even so, we contend that these limitations cannot explain the observed differences in framing and analysis. We left the experts completely free in their choice of scope and encouraged them to request whatever information they considered relevant.

Another consideration is that the stakeholders had limited influence over the objectives and institutions laid down by higher authorities-although they 
frequently challenged them-and this depoliticized the process to some extent. It is possible that our findings are limited to such contexts, which we can expect to find often in the future, for example, in relation to the implementation of the Water Framework Directive and the Natura 2000 agenda.

\section{CONCLUSIONS}

By comparing two policy development processes for the same case, one using a participatory approach and the other using an expert-based approach, we hoped to improve our understanding of the influence of stakeholders on framing and analysis and on the knowledge base used. Not surprisingly, we found large differences in both process and outcome. Active participation of stakeholders in policy development on a controversial issue is bound to show a wider variety of frames and generate a more passionate and dynamic discourse. In the participatory process, reframing occurred more often and involved more radical proposals (giving up nature objectives, leaving the decision to politicians, buying out several farms and relocating others). Our analysis of both processes in terms of uncertainties and the way they were handled was effective in articulating the important episodes and elucidating the differences in the framing and analysis and the use of knowledge during policy development.

Our study confirmed several findings from previous empirical research. Firstly, stakeholder involvement in policy development increased the quality of the knowledge base. Secondly, it widened the frame to include important stakeholder criteria and additional options. In the expert-based process, the frame was limited to what the water board would be able to achieve. We see this as avoidance of process uncertainty. The involvement of stakeholders made process uncertainty much more prominent, and the effort to resolve the institutional and strategic uncertainty resulted in the adoption of a broader frame. We see the wish for a "once and for all" settlement of the prolonged conflict as an important driver for the differences in uncertainty handling. The low tolerance of process uncertainty eventually led to a policy that was not adaptive. An interesting observation is the rejection in the participatory process of relying on expert judgment as the main method of handling substantive uncertainty on a controversial topic. Instead, the stakeholders opted for a more formalized modeling procedure to make knowledge acquisition traceable, combined with explicit communication of uncertainty.

The explanations we offer for the observed phenomena are tentative. More research is needed to establish whether they can be generalized beyond this case study. Having established the practical feasibility of a "one case, two processes" comparison, we believe that this research design merits further development and replication because it allows scrutiny of framing and analysis while case-specific conditions are (more) controlled. We speculate that the applied focus on uncertainty enhances insight into alternative choices for process management in a policy development process and we envisage its application not only in case comparison but also in process design and evaluation. Finally, our study suggests that more research into the interaction between the handling of different types of uncertainty is warranted.

Responses to this article can be read online at: http://www.ecologyandsociety.org/voll6/iss 1/art51/ responses/

\section{Acknowledgments:}

This research is part of the Integrated Project AquaStress (http://www.aquastress.net) financed by the 6th EU Framework Programme for Research and Technological Development (FP6). Special thanks are due to Nicolien van der Fluit, the water board Velt en Vecht, and the members of the sounding board group of the Bargerveen GGOR process. Furthermore, we are very grateful to Jacques Esenkbrink, Zwannie Visser, and Martijn Maneschijn of water board Reest en Wieden for their participation in the development of the expertbased GGOR. We also thank Maarten Krol, Sabine Möllenkamp, Katherine Daniell, and two anonymous reviewers for their constructive and inspiring comments on earlier drafts of this article.

\section{LITERATURE CITED}

Abbott, J. 2005. Understanding and managing the unknown. The nature of uncertainty in planning. Journal of Planning Education and Research 24 (3):237-251. 
Arnstein, S. 1969. A ladder of citizen participation. Journal of the American Planning Association 35 (4):216-224.

Baccaro, L. 2006. Civil society meets the state: towards associational democracy? Socio-Economic Review 4(2):185-208.

Barreteau, O., P. W. G. Bots, and K. Daniell. 2010. A framework for clarifying "participation"in participatory research to prevent its rejection for the wrong reasons. Ecology and Society 15(1):1. [online] URL: http://www.ecologyandsociety.org/vol15/ iss2/art1/.

Beierle, T. C., and J. Cayford. 2002. Democracy in practice: public participation in environmental decisions. Resources for the Future, Washington, D.C. USA.

Beierle, T. C., and D. M. Konisky. 2001. What are we gaining from stakeholder involvement? Observations from environmental planning in the Great Lakes. Environment and Planning $C$ : Government and Policy 19:515-527.

Biggs, S. D. 1989. Resource-poor farmer participation in research: a synthesis of experiences from national agricultural research systems. OFCOR-Comparative study paper 3 International Service for National Agricultural Research, The Hague, The Netherlands.

Bots, P., R. Bijlsma, Y. von Korff, N. van der Fluit, and H. Wolters. 2011. Supporting the constructive use of existing hydrological models in participatory settings: a set of 'rules of the game'. Ecology and Society in press.

Brugnach, M., A. Dewulf, C. Pahl-Wostl, and T. Taillieu. 2008. Toward a relational concept of uncertainty: about knowing too little, knowing too differently, and accepting not to know. Ecology and Society 13(2):30. [online] URL: http://www.ecolog yandsociety.org/vol13/iss2/art30.

Clark, J., and J. Murdoch. 1997. Local knowledge and the precarious extension of scientific networks: a reflection on three case studies. Sociologia Ruralis 37(1):38-60.

De Marchi, B. 2003. Public participation and risk governance. Science and Public Policy 30(3):171176.
Dewulf, A., B. Gray, L. Putnam, R. Lewicki, N. Aarts, R. Bouwen, and C. M. J. van Woerkum. 2009. Disentangling approaches to framing in conflict and negotiation research: a meta-paradigmatic perspective. Human Relations 62(2):155-193.

Ehrmann, J. R., and B. L. Stinson. 1999. Joint factfinding and the use of technical experts. Pages 375400 in L. Süsskind, S. Mc Kearnan, and J. ThomasLarmer, editors. The consensus building handbook. A comprehensive guide to reaching agreement. Sage Publications, London, UK.

Elster, J. 1989. The cement of society: a study of social order. Cambridge University Press, Cambridge, UK.

Entman, R. M. 1993. Framing: towards clarification of a fractured paradigm. Journal of Communication 43(4):51-58.

EU. 2000. Directive 2000/60/EC of the European Parliament and of the Council establishing a framework for the community action in the field of water policy. Official Journal (OJ L 327). [online] URL: http://ec.europa.eu/environment/water/waterframework/index en.html.

Fiorino, D. J. 1990. Citizen participation and environmental risk: a survey of institutional mechanisms. Science, Technology \& Human Values 15(2):226-243.

Fischer, F. 2003. Reframing public policy. Oxford University Press, Oxford, UK.

Fritsch, O., and J. Newig. 2006. Improving environmental quality through participation? A critical perspective on the effectiveness of public participation. Proceedings of the Conference on Participatory Approaches in Science and Technology, 4-7 June 2006, Edinburgh, U.K. [online] URL: http://www.macaulay.ac.uk/PATHc onference/outputs/PATH abstract 2.3.2.pdf

Kahneman, D., and A. Tversky, editors. 2000. Choices, values, and frames. Cambridge University Press, Cambridge, UK.

Kickert, W. J. M., E. H. Klijn, and J. F. M. Koppenjan, editors. 1997. Managing complex networks: strategies for the public sector. Sage Publications, London, UK. 
Koppenjan, J., and E. H. Klijn. 2004. Managing uncertainties in networks. A network approach to problem solving and decision making. Routledge, London, UK and New York, USA.

Laird, F. N. 1993. Participatory analysis, democracy, and technological decision making. Science, Technology and Human Values 18(3):341361.

Maxim, L., and J. P. van der Sluijs. 2007. Uncertainty: cause or effect of stakeholders' debates? Analysis of a case study: the risk for honeybees of the insecticide Gaucho. Science of the Total Environment 376:1-17.

Morgan, M. G., and M. Henrion. 1990. Uncertainty: a guide to dealing with uncertainty in quantitative risk and policy analysis. Cambridge University Press, Cambridge, UK.

Putnam, L. L., and M. Holmer. 1992. Framing, reframing and issue development. Pages 128-155 in L. L. Putnam, and M. Roloff, editors. Communication and Negotiation. Sage Publications, London, UK.

Rhodes, R. A. W. 1997. Understanding governance: policy networks, governance, reflexivity and accountability. Open University Press, Buckingham, UK.

Rowe, G., R. Marsh, and L. J. Frewer. 2004. Evaluation of a deliberative conference using validated criteria. Science, Technology, \& Human Values 29(1):88-121.

Scharpf, F. W. 1997. Games real actors play. Actorcentered institutionalism in policy research. Westview Press, Boulder, Colorado, USA.

Schön, D. A., and M. Rein. 1994. Frame reflection: toward the resolution of intractable policy controversies. Basic Books, New York, NY, USA.

Smith Korfmacher, K. 2001. The politics of participation in watershed modeling. Environmental Management 27(2):161-176.

Stern, P. C., and V. Fineberg. 1996. Understanding risk: informing decisions in a democratic society.
National Research Council. Committee on Risk Characterization. National Academy Press, Washington, D.C., USA.

Termeer, C. J. A. M., and J. F. M. Koppenjan. 1997. Managing perceptions in networks. Pages 79-97 in W. J. M. Kickert, E. H. Klijn, and J. F. M. Koppenjan, editors. Managing complex networks: strategies for the public sector. Sage Publications, London, UK.

Van Asselt, M. B. A. 2005. The complex significance of uncertainty in a risk era: logics, manners and strategies in use. International Journal of Risk Assessment and Management 5(2/3/4):125150.

Van de Riet, A. W. T. 2003. Policyanalysis in multiactor policy settings: navigating between negotiated nonsense and superfluous knowledge. Eburon Publishers, Delft, The Netherlands.

Walker, W. E., P. Harremoës, J. Rotmans, J. P. van der Sluijs, M. B. A. van Asselt, P. Janssen, and M. P. Krayer von Krauss. 2003. Defining uncertainty: a conceptual basis for uncertainty management in model-based decision support. Integrated Assessment 4(1):5-17.

Walker, W. E., and V. Marchau. 2003. Dealing with uncertainty in policy analysis and policymaking. Integrated Assessment 4(1):1-55.

Walton, R. E., and R. B. McKersie. 1965. A behavioral theory of labor negotiation. McGrawHill, New York, USA.

Wynne, B. 1992a. Uncertainty and environmental learning: reconceiving science and policy in the preventive paradigm. Global Environmental Change 2(2):111-127.

Wynne, B. 1992b. Misunderstood misunderstanding: social identities and public uptake of science. The Public Understanding of Science 1:281-304.

Wynne, B. 1996. May the sheep safely graze? A reflexive view of the expert-lay knowledge divide. Pages 165-198 in S. Lash, B. Szerszynski, and B. Wynne, editors. Risk, environment and modernity: towards a new ecology. Sage Publications, London, UK. 
APPENDIX 1. Questionnaires used to evaluate the participatory approach.

We asked the participants' view on the context and process management of the participatory process. Presenting statements, we asked them to choose one of the following responses: strongly agree, agree, neither agree nor disagree, disagree or strongly disagree.

\section{Questionnaire to evaluate the context of the participatory approach}

Statements:

1. At the beginning of the process, there was no or only a little conflict between the goals/objectives of the various participants.

2. At the beginning of the process, personal relationships between the participants were good.

3. At the beginning of the process, participants trusted the water board.

4. At the beginning of the process, participants were interested not only in reaching their own objectives but also the objectives of the group.

5. At the beginning of the process, participants were confident that the approach would help reach the group's objectives.

6. At the beginning of the process, there were only very few problems to be addressed.

7. At the beginning of the process, water managers and other decision-makers involved were open to the opinion of others.

8. At the beginning of the process, participants were used to speaking up in a group and to frankly sharing their opinions.

9. At the beginning of the process, the geographical and legal boundaries of the problem were clearly defined.

10. Enough time and funds are available to meet the targets of the process.

\section{Questionnaire to evaluate the process management of the participatory approach}

Statements:

1. In my opinion, the participants in this process fairly represent the members of the public who will be affected by the issues raised in it.

2. In my opinion, the process has been run in an unbiased way (i.e., without undue influence from process organizers).

3. In my opinion, this process has taken place at a sufficiently early stage in the policy formulation procedure to allow participants to have some genuine influence (i.e., not at a stage where most of the important decisions have already been made).

4. In my opinion, the recommendations that originate from participants in this process will be implemented by the organizers of the exercise.

5. In my opinion, the activity's process has been transparent (i.e., all interested parties are readily able to see what is going on if they want).

6. In my opinion, the process provided me with sufficient resources (financial, number of meetings and information) to take part in it effectively.

7. In my opinion, the nature and scope of the task was well defined (i.e., I understood precisely what was required from me in the process).

8. In my opinion, the process was well organized and managed on a practical level (i.e., the understanding of key concepts by participants was ensured during the process, discussion and decision-making procedures were appropriate and kept on track and the process was skillfully adapted to unforeseen developments when this was necessary).

9. In my opinion, this process would seem to be cost effective (i.e., the outcome of the activity could not be achieved in a more costeffective way). 